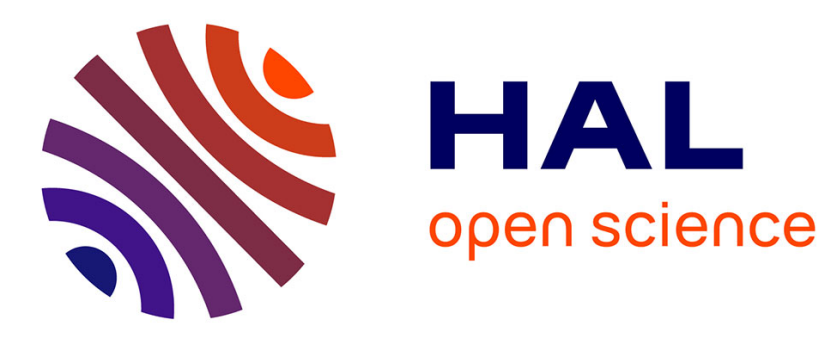

\title{
Fracture in duplex structures
}

\author{
J. Foct, N. Akdut, T. Magnin, R. Taillard, J.-B. Vogt
}

\section{To cite this version:}

J. Foct, N. Akdut, T. Magnin, R. Taillard, J.-B. Vogt. Fracture in duplex structures. Journal de Physique IV Proceedings, 1993, 03 (C7), pp.C7-597-C7-604. 10.1051/jp4:1993798 . jpa-00252218

\section{HAL Id: jpa-00252218 https://hal.science/jpa-00252218}

Submitted on 1 Jan 1993

HAL is a multi-disciplinary open access archive for the deposit and dissemination of scientific research documents, whether they are published or not. The documents may come from teaching and research institutions in France or abroad, or from public or private research centers.
L'archive ouverte pluridisciplinaire HAL, est destinée au dépôt et à la diffusion de documents scientifiques de niveau recherche, publiés ou non, émanant des établissements d'enseignement et de recherche français ou étrangers, des laboratoires publics ou privés. 


\title{
Fracture in duplex structures
}

\author{
J. FOCT, N. AKDUT ${ }^{*}$, T. MAGNIN, R. TAILLARD and J.-B. VOGT
}

Université de Lille I, Laboratoire de Métallurgie Physique, Associé CNRS 234, 59655 Villeneuve d'Ascq cedex, France

*IMM-RWTH, Aachen, Germany

\begin{abstract}
This paper aims to discuss and analyse the basics of crack propagation mechanisms in duplex structures (DS) and to model the role of crack formation and crack healing on forming of DS.
\end{abstract}

\section{I - INTRODUCTION}

Among two phases materials, the concept of Duplex microstructure has not been adequately defined (1-6). To meet this need, the features that characterize a Duplex are (7) :

* The two phases have the same interatomic characteristics, i.e. both are metallic or both are ionic and so their properties are not widely dissimilar;

* Their relative abundances are comparable i.e. the concentration of each phase is within the limits $10-90 \%$;

* The morphology can not be described by a limited number of parameters.

Within these definitions duplex steels $(\alpha / \gamma)$ some copper alloys $(\alpha / \beta$ brass) and titanium alloys are considered to be Duplex as well as dual steels $\left(\alpha / \alpha^{\prime}\right)$ and ceramic composites such as zirconia: alumina and $\alpha: \beta^{\prime}$ sialons.

Duplex structures appear to constitute a specific class of materials of which the textural and topological description is far from being achieved. The variation of the properties in the space, resulting from the heterogeneity of the two phases material, creates a gradient of properties. If the gradient of toughness is considered, $\overrightarrow{\text { grad }} \mathrm{G}_{C}$, this gradient is for the duplex structure intermediate between the corresponding values in polycrystal and composites. The fluctuations of the crack propagation rate energies $\overrightarrow{g r a d} G$ and $\overrightarrow{g r a d} G_{C}$ correspond to crack propagation mechanisms such as deviation, branching... which need more energy than in single phase materials.

The mechanical behaviour of D.S. involves specific microscopic mechanisms, crack healing, mechanical welding and alloying, mass transfer... the under-standing of which will be discussed below.

\section{II - PROPAGATION OF CRACKS IN DUPLEX STRUCTURES}

Two main ideas are intuitively and sometimes explicitly used when the toughness of duplex microstructure is studied :

i) the phase boundaries create obstacles for the propagation of cracks.

ii) the duplex structure favours crack deviation and branching therefore 
increases the energy needed to propagate the cracks.

In order to take these phenomena into account (7) the critical crack energy release rates $G_{C}^{\alpha}$ and $G_{C}^{\gamma}$ have to be considered. One may fear that an energy criterion would mask the orientation effects we intend to consider, because $G_{C}$ is a scalar parameter. In fact, the orientation factors are not neglected if the different $G_{C}$ values, corresponding to mode $I$, II and III propagations, are considered. The $G_{C}^{\alpha}$ and $G_{C}^{\gamma}$ parameters correspond to the maximum extension of the plastic zone at the crack tip and therefore to the ability of the material to accommodate the externally applied strains by plastic deformation. Usually, the $G_{C}$ values are considered as macroscopic and refer to homogeneous isotropic specimens. It will be supposed here that $G$ is not homogeneous and not isotropic. $G$ is determined locally and depends on the propagation mode and propagation direction $P_{i j}: G_{C}\left(\vec{X}, P_{i j}\right)$. Clearly, the main change in $G_{C}\left(\vec{X}, P_{i j}\right)$ is the nature ( $\alpha$ or $\gamma$ ) of the medium in $\vec{X}$. This is the reason why in single phase materials only the homogeneous character of $G$ is considered. As a first approximation for a Duplex Structure, three cases have to be considered: the mean value of $\mathrm{G}_{\mathrm{C}}$ in the different phases $\bar{G}_{C} \alpha$ and $\bar{G}_{C} \gamma$ and at the interface $\bar{G}_{C}{ }^{\alpha / \gamma}$. The plastic accommodation at the interface can be considered as a function of plastic deformations in both $\alpha$ and $\gamma$ phases. Although the following assumption (8):

$$
\bar{G}_{C}^{\alpha / \gamma}=\frac{1}{2}\left(\bar{G}_{C}^{\alpha}+\bar{G}_{C}^{\gamma}\right)
$$

is not very precise, because the plastic deformation of a ductile phase $\alpha$ cannot easily compensate an eventual absence of plasticity of the other phase $\gamma$ it can be accepted for duplex structure because as previously mentioned the properties of both phases are not widely dissimilar. The validity of (1) is only guaranteed when the bonding between $\alpha$ and $\gamma$ is strong enough as previously mentioned for steel-coatings. If $B_{\alpha / \gamma}, B_{\alpha}, B_{\gamma}$ are the strengths (-enthalpies) of the bonding on planes parallel to the interface $\alpha / \gamma$, at $\alpha / \gamma$ and inside $\alpha$ and $\gamma$, it will be proposed that (9):

$$
\bar{G}_{C}^{\alpha / \gamma}=\frac{1}{2} F\left(\frac{B_{\alpha / \beta}}{B_{\alpha}}\right) G_{C}^{\alpha}+\frac{1}{2} F\left(\frac{B_{\alpha / \gamma}}{B_{\gamma}}\right) G_{C}^{\gamma}
$$

where $F$ is a growing function of $\alpha / \gamma$ bonding vanishing when $\frac{B_{\alpha / \gamma}}{B_{\alpha}}$ is small and near 1 when $\frac{\mathrm{B}_{\alpha / \gamma}}{\mathrm{B}_{\alpha}} \geq 1$

Equation (2) clearly shows that the "toughness" of the bonding depends on two properties: on the one hand the chemical bonding between both phases, and on the other hand on the plasticity of each $\alpha$ and $\gamma$ phases. From relation (2) one can therefore distinguish two extreme cases :

i) The boundary $\alpha / \gamma$ is weak $F \rightarrow 0 \quad \bar{G}_{C} \alpha / \gamma \rightarrow 0$

when cracks propagate inside $\alpha$ or $\gamma$ and reach the $\alpha / \gamma$ interface they will develop further in the $\alpha / \gamma$ interface

ii) The bonding $\alpha / \gamma$ is strong $\bar{G}_{C}^{\alpha}>\bar{G}_{C}^{\alpha / \gamma}>\bar{G}_{C}{ }^{\gamma}$ :

If the toughness difference is large enough the cracks will be confined in the more brittle phase $\gamma$ (figure 1 ).

In fact it is well known that the crack propagation criterion is $G>G_{C}$ where $G$ is the available energy which can be dissipated by the propagation of the crack. 
$G$ depends on the geometry of the crack $\left(g_{c}\right)$ and on the stresses $(\sigma)$ in the specimen $G\left(\sigma, g_{C}\right)$. When the morphology is complicated, the determination of the actual stress is very difficult. Therefore the previous conclusions were compared with the experimental results obtained with zinc coating on steel where the interfaces are roughly planar (8) and with duplex wires of $\mathrm{NbTi}$ superconducting fibers drawn in a copper matrix (10). In both cases the chemical affinity between both phases was important and led to the formation of brittle intermetallic compounds strongly bonded with $\alpha$ and $\gamma$ and where the cracks stood, as long as the mean total deformation of the specimen was low. It is worth emphasizing that the accommodation of the macroscopic externally applied strain cannot be insured by plasticity in the most brittle phase although the plasticity of the ductile phase bounds the extension of the cracks, at least when the local $G$ in the ductile phase is less than $G_{C}$. An increase of $G$ in the ductile phase can however occur either by local increase of the internal stress due to coarse microstructure or (and) to local stress concentration and high triaxiallity such as created near an inclusion.

This behaviour of duplex structures is exemplified by micrographs obtained in $\mathrm{NbTi}-\mathrm{Cu}$ duplex systems (Figures 2 and 3 ). A large $\mathrm{TiCu}$ intermetallic compound particle (Figure 2A) creates an important triaxial stress field (tensile stress along the fiber and compression perpendicularly) which favours a shear crack of the fiber (Fig. 2A) and of the composite (Fig. 2B). When the TiCu intermetallic layer is continuous, a crack network is initiated in the brittle phase, stops in the more ductile NbTi alloys (Fig. 3A) or the composite when the applied stress (and therefore $\mathrm{K}$ and $\mathrm{G}$ ) increases (Fig. 3B)... When the formation of CuTi intermetallic compound is avoided the same bending as in Figure 3 does not lead to the ruin of the material (Fig, 4).

\section{III - FATIGUE CRACKS}

It has been established that the initiation of fatigue cracks occurs at the surface of the specimen and that this phenomenon is related with the cyclic plastic deformation of the grain giving rise to persistent slip bands, extrusions, intrusions and microcracks. For this stage the length of the cracks is similar to the grain size and before propagation occurs the crack has to overcome the obstacle formed by grain boundaries and, in DS, by phase boundaries. Because the initiation stage for crack formation in fatigue is related to plasticity it is to be expected that in DS the more ductile phase will be the seat of the microcrack initiation but to our knowledge this has not been clearly established except for duplex stainless steel (11-13) where crack initiation in the ductile $\gamma$ phase was proved to occur for low amplitude of plastic deformation $\Delta \varepsilon_{\mathrm{p}} / 2=310^{-4}$ and in $\alpha$ for higher $\Delta \varepsilon_{\mathrm{p}}\left(\Delta \varepsilon_{\mathrm{p}} / 2=410^{-3}\right)$.

The propagation of a fatigue crack is preceded by the accumulation of a damage induced by the plastic deformation at the tip of the crack, therefore the arguments based on $G_{C}$ in previous paragraphs do not strictly hold for fatigue cracks and the atomic bonding at the phase boundary plays a deciding role. Basically, the propagation of the fatigue crack is related with the irreversible part of $G$ dissipated ahead of the crack front. If $B_{\alpha / \gamma}$ is weak the plastic deformation may not be completely transmitted from one phase to the other and a crack branching is likely to occur at the interface. Reciprocally when $B_{\alpha / \gamma}$ is strong the plastic deformation will be transmitted from one phase to the other and the crack will not deviate. The fact that the crack does not deviate does not implicate that the crack growth rate $\mathrm{da} / \mathrm{dn}$ does not change. Experimental results and simulation of crack coalescence in ferrite-perlite mixture show that the role of obstacle played by phase boundaries holds. When the delay created by phase boundaries on crack propagation can be neglected a "series-type" law for the mean propagation rate $d \bar{a} / \mathrm{dn}$ is to be proposed ( 8 ) : 


$$
\frac{2}{\frac{d \bar{a}}{d n}}=\frac{1}{\left(\frac{d a}{d n}\right)_{\alpha}}+\frac{1}{\left(\frac{d a}{d n}\right)_{\gamma}}
$$

In order to insure the consistency of equation (3) the variation $\Delta K$ of the stress intensity factor in the different phases should be the same. Except for planar interfaces parallel to the crack tip, the former condition is nearly impossible to obey : scanning electron micrographs show that the front of the crack is not a straight line but presents loops and meanders. This serpent shape of the crack may or may not coincide with an $\alpha / \gamma$ frontier depending on the relative brittleness of the phases. In all cases it is expected that the concavity of the crack front is either towards the cracked or towards the un-cracked material depending on the situation either in the more or in the less brittle constituent. Figure 5 shows an example of duplex steel for which the fatigue crack propagation in the more brittle phase occurs by a cleavage-like mechanism similar to that observed by tensile test (14). The crack propagation is then radial towards the more ductile phases as shown by two striation direction nearly perpendicular to each other. Frequently the competition between different propagation lead to interferences pattern of the striations characterized by a "dinosaur spine" look. Meanwhile the possible mechanisms of the slowing down of the fatigue crack by a duplex structure are still unclear.

\section{IV - FORMING OF DUPLEX MICROSTRUCTURES}

Experiment shows that the forming of duplex alloys is usually much easier than expected and possible when the same thermomechanical treatment would lead to the destruction of the single brittle phase deprived of its association with a more ductile one. These observations refer to many duplex systems such as austenoferritic stainless steel, $\alpha-\beta$ brass, titanium alloys, technical superconductors... In $\mathrm{Cu}-\mathrm{Fe}$ alloys subjected to a sequence of rolling passes the striking feature was the early appearance of cracks and later their disappearance.

This result can be qualitatively summarized by the schematic diagram which shows that the crack density and crack length versus rolling deformation attain a maximum near 30\%. Another striking observation to be emphasized is the refinement of the microstructure (5).

Two phenomena have to be taken into account in order to understand former experimental results (5) :

* The mechanical rewelding of crack surfaces.

* The competition between $\varepsilon_{d}$ and $\varepsilon_{c}$ for accommodating the macroscopic deformation $\varepsilon_{\mathrm{m}}$ of the sample. $\varepsilon_{\mathrm{d}}$ is the deformation which results from plasticity i.e. essentially dislocation multiplication and dislocation glide. $\varepsilon_{C}$ is the deformation resulting from the formation of cracks.

The following equation results from these two sources of a microscopic deformation :

$$
\dot{\varepsilon}_{\mathrm{m}}=\dot{\varepsilon}_{\mathrm{d}}+\dot{\varepsilon}_{\mathrm{C}}
$$

$\dot{\varepsilon}_{\mathrm{d}}$ is given by the Orowan's relationship :

$$
\dot{\varepsilon}_{\mathrm{d}}=\mathrm{NbV}
$$

Because during rolling the annihilation and creation of dislocations balance, $\dot{\varepsilon}$ is nearly proportional to $\mathrm{v}$ and therefore an increasing function of the stress $\sigma$. Meanwhile $\sigma$ is upperbounded by the toughness of the material :

$$
\sigma<\frac{\mathrm{K}_{\mathrm{C}}}{\sqrt{\ell}}
$$


where $\ell$ is a metric parameter related with the microstructure, in the case of polycrystals the grain size d.

When the microstructure parameter $\ell$ decreases, i.e. by refinement of the microstructure $\dot{\varepsilon}_{\mathrm{d}}$ increases. If $\ell$ is larger than a critical value $\ell_{\mathrm{c}}$ the macroscopic value $\dot{\varepsilon}_{\mathrm{m}}$ have to be accommodated by formation of cracks $\dot{\varepsilon}_{\mathrm{c}}>0$.

This interpretation in the form of a critical size of the microstructure $\ell_{C}$, for which cracks form when $\dot{\varepsilon}_{\mathrm{m}}$ cannot be accommodated by plasticity in $\alpha, \gamma$ or $\alpha / \gamma$. divides the ( $\dot{\varepsilon}_{\mathrm{m}}$ vs. $\sqrt{\ell}$ )-space into four different domains 0 , I, II, III, defined in figure 6 and indicating if and where cracks form. Because in a duplex structure high stress concentration exists at the interface, the easiest zone for crack growth is the $\alpha / \gamma$ interface. The domain I, which corresponds to the $\alpha / \gamma$ interface is reached in the first place when $\dot{\varepsilon}_{\mathrm{m}}$ and/or $\sqrt{\ell}$ increase. Then the cracks form in the most brittle phase, which in the present case is $\alpha$ (II). A last domain (IV) corresponds to cracks crossing the $\alpha$ and $\gamma$ phase many times and, therefore, are likely to reach the surface of the specimen, whose size is L.

A description of the material behaviour during the rolling process may be given now. Starting with a duplex microstructure whose scale parameter is $l_{0}$, a first set of rolling passes leads the cracks to propagate in one or several I, II, III domains. As long as the cracks are restricted to small sizes, i.e. not reaching IV, the crack surfaces may weld during a second set of rolling passes under the applied hydrostatic and deviatoric states of stress. This healing stage, $B$, is also accompanied by a refinement of the microstructure and reduces the initial scale $\ell_{0}$ to the smaller value $\ell_{1}$. Supplementary rolling does not lead to new cracks because the plastic deformation now proceeds in a finer microstructure, which is able to bear a higher stress level (stage C).

\section{$\mathrm{V}$ - CONCLUSION}

Important fluctuations of the critical crack propagation energy $G_{C}$ and critical stress intensity factor $\mathrm{K}_{\mathrm{C}}$ result from the duplex structure. These fluctuations lead to crack propagation, crack arrest, crack branching and crack deviation mechanisms which appreciably differ from those observed in single phase materials. Advantage of this behaviour can be taken during processing as well as during use of duplex materials.

\section{REFERENCES}

[1] HORNBOGEN, F., "Geflüge und Festigkeit von Metallen," 2 . Metallkde, 68 (1977), 455-469.

[2] FISCHMEISTER $\mathrm{H}$. and KARLSSON B., "Plastizitätseigenschaften grob-zweiphasiger Werkstoffe," Z. Metallkde, 68 (1977), 311-327.

[3] BECKER J., HORNBOGEN E. and STRATMANN P., "Dual Phasen - Gegüge," $z$. Metallkde, 71 (1980), 27-31.

[4] POECH M.H. and FISCHMEISTER H., "Mechanische Eigenschaften von Martensit Austenit - Legierungen," Z. Metallkde, 83 (1992), 176-182.

[5] FOCT $j$., AKDUT $N$. and GOTTSTEIN G., "Why are Duplex microstructures easier to form than expected?" Scripta Metall. et Mat., 27 (1992), 1033-1038.

[6] CANOVA G.R, WENK H.R. and MOLINARI A., "Deformation Modelling of Multi-Phase Polycrystals," Acta Metall. Mater., 40 (1992), 1519-1530.

[7] FOCT J., Duplex Alloys and their relationship with composites, Advanced Composites 93, Chandra Ed., TMS 
[8] FOCT J., "Relaxation of stresses by cracks in intermetallic coatings : Application to galvanizing," Scripta Metall. et Mat., 28 (1993), 127-132.

[9] FOCT J., Role of high nitrogen alloying on the mechanical behaviour of duplex steel, HNS 93, Kiev,Ukraine, to be published.

[10] TAILLARD R., BRUZEK C.E. and HOANG-GIA-KY, (To be published in I.E.E.E. Trans Magnetica, 1993).

[11] MAGNIN T. and LARDON J.M., "Cyclic Deformation Mechanisms of a Two phase Stainless Steel in various Environmental Conditions," Mater. Sci. Engn., A104 $(1988), 21-28$.

[12] MAGNIN T., LECOZE J. and DESESTRET A., "Twinning and Stress Corrosion Cracking of ferrite phases of Duplex Stainless Steels," Proc. Conf. on D.S.S., ed. R.A. Lula, (ASM 1983) 535.

[13] FOCT J., MAGNIN T., PERROT P and VOGT J-B., Duplex Stainless Steels 91 , ed. J. Charles and S. Berhhardson, (Les Editions de Physique 1991) 49-65.

[14] FOCT J.and AKDUT N., Cleavage-like fracture of austenite in duplex stainles steel, Scripta Met. (1993).

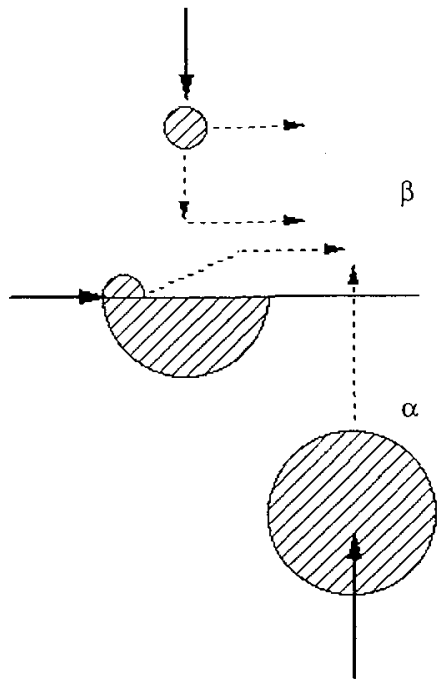

a)

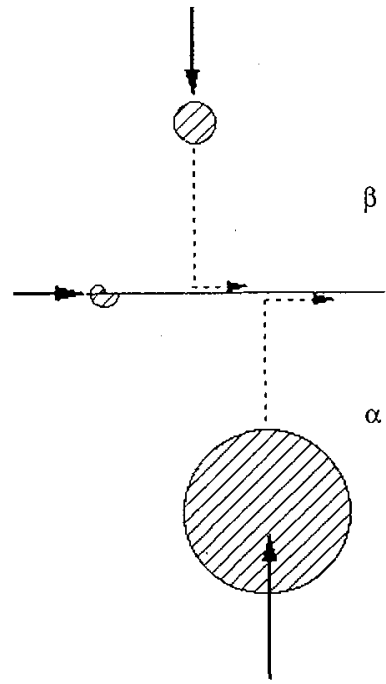

b)

Figure 1 : Quantitative extension of the plastic zone for crack propagation in $\alpha$, $\beta$ and $\alpha / \beta$, continuous arrows indicate cracks and dotted arrows their possible progression. (Ref. 7)

1a) the $\alpha / \beta$ bonding is strong.

1b) the $\alpha / \beta$ bonding is weak. 

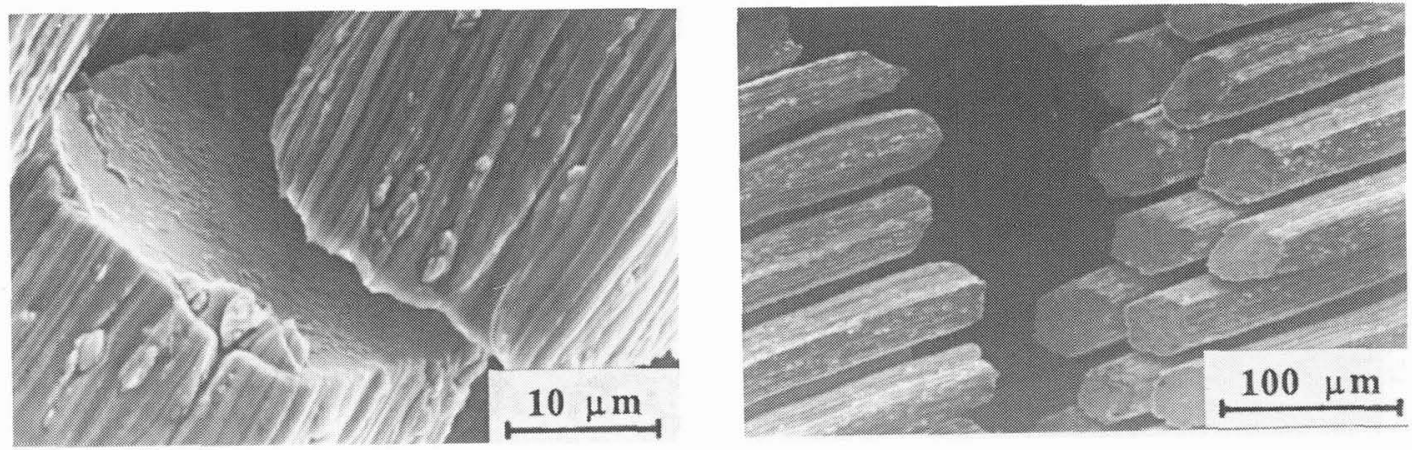

Figure 2 : a) Intermetallic particles $(1-3 \mu \mathrm{m})$ formed during thermomechanical treatment of NoTi wires in a Cu matrix, lead to high triaxiallity of the stress field and the crack is driven by shear. b) In the same conditions as figure 1 a the shear fracture crosses both phases and therefore several filaments.
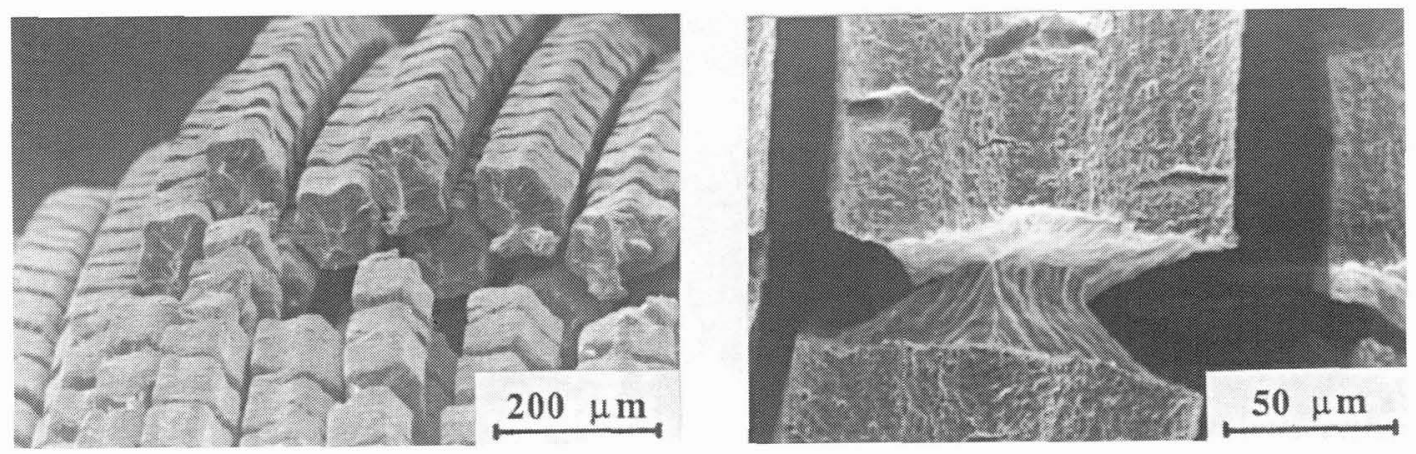

Figures $3 a-3 b$ : A continuous intermetallic layer obtained by thermal treatment is the seat of crack initiation. Depending on the stress amplitude created by bending the crack may (Figure 3a) or may not (Figure 3b) cross the filament. 


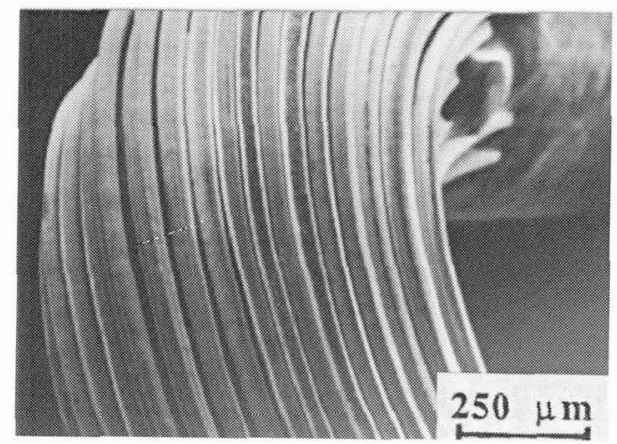

Figure 4 : When the formation of a brittle intermetaliic layer is avoided the same conditions of bending those of Fig. $3 a-3 b$ do not lead to formation of cracks.

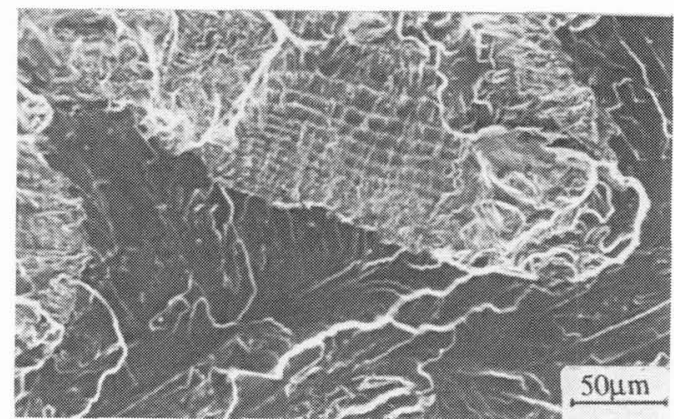

Figure 5: Propagation of fatigue cracks in a duplex stainless steel containing $\quad 0.62 \% \mathrm{~N}$. The fracture surface of $\gamma$ austenite is cleavagelike and two striation systems nearly perpendicular to each other are observed in $\alpha$ ferrite (Arrows).

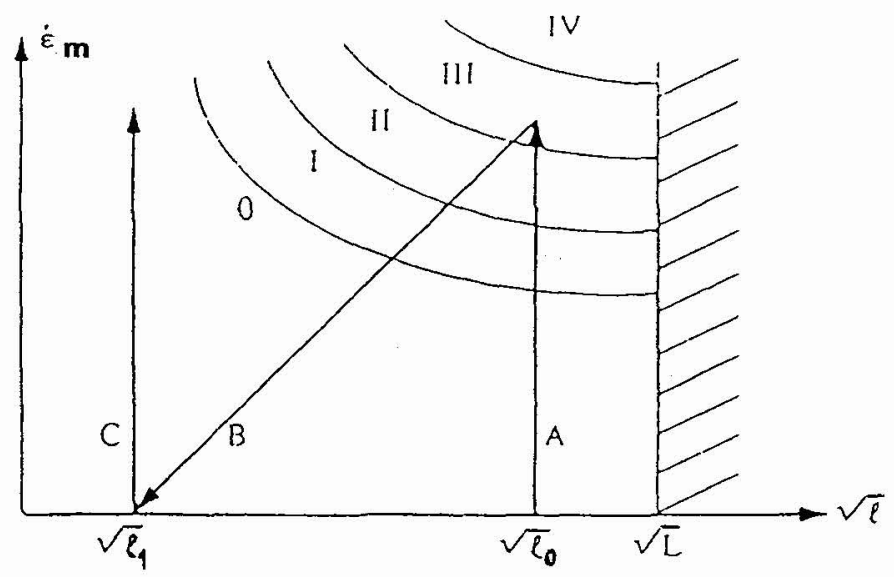

Figure 6: Qualitative mapping of the crack evolution with rolling in a duplex $\alpha-\gamma$ microstructure as a function of a microstructural scale parameter $\ell$ and the macroscopic deformation rate $\dot{\varepsilon}_{\mathrm{m}}$ (Stage A : rolling passes introduce cracks much smaller than L, Stage B : healing of the cracks and refinement of the microstructure $\ell_{1}<\ell_{0}$, Stage $C$ : supplementary rolling for which coordinates stay in the safe domain 0 ). (Ref. 5) 